\title{
Malignant melanoma of the choroid in a husband and wife
}

\author{
JERRY A. SHIELDS, ${ }^{2}$ JAMES J. AUGSBURGER, ${ }^{12}$ VIOLETA ARBIZO,${ }^{3}$ \\ JOSEPH F. MORRISON JR, ${ }^{4}$ AND ALFRED C. LUCIER ${ }^{12}$
}

From the 'Oncology Service, the ${ }^{2}$ Retina Service and the ${ }^{3}$ Pathology Department, Wills Eye Hospital, Jefferson Medical College, Thomas Jefferson University, Philadelphia, and ${ }^{4}$ private practice in Wilkes-Barre, $P A, U S A$

SUMMARY A 52-year-old man was diagnosed as having a large malignant melanoma of the choroid in the right eye. Six years later his 58-year-old wife of almost 40 years was diagnosed as having a large malignant melanoma of the choroid in her left eye. In both patients the diagnosis was confirmed histologically following enucleation. Electron microscopy failed to reveal evidence of viral particles within the tumours. The implications of this unusual occurrence are discussed.

The occurrence of identical cancers in a husband and wife is extremely rare. In 1980 Russ and Scanlon accumulated data on 11 married couples with histologically identical malignant tumours. ${ }^{1}$ In their series two couples had cutaneous melanoma, three had carcinoma of the breast, two had carcinoma of the kidney, and one couple each had fibrosarcoma, carcinoma of the floor of the mouth, carcinoma of the colon and rectum, and carcinoma of the nasopharynx. Malignant melanomas of the uveal tract are not known to occur in spouses and only rarely occur in blood relatives. ${ }^{12}$ This report describes the occurrence of malignant melanoma of the choroid in a husband and wife. We are not aware of any previously published cases of connubial uveal melanomas.

\section{Case reports}

\section{CASE 1 (hUSBAND)}

A 52-year-old white man consulted his ophthalmologist in November 1975 because of blurred vision in the right eye. His past medical history was noncontributory and the family history revealed only that his mother had died of gastric carcinoma at the age of 83 . The patient had worked for many years as a welder.

His best corrected visual acuities were $6 / 24$ in the right eye and $6 / 6$ in the left eye. Intraocular

Correspondence to J. A. Shields, MD, Oncology Service, Wills Eye Hospital, Ninth and Walnut Streets, Philadelphia, PA 19107 , USA. pressures were $10 \mathrm{mmHg}$ OD and $7 \mathrm{mmHg}$ OS. The entire left eye and the anterior segment of the right eye were normal. His irides were brown in colour with no heterochromia.

Fundus examination of the right eye disclosed a raised grey-brown choroidal mass which extended temporally from the foveola and measured $11 \times 11 \mathrm{~mm}$ in diameter and $4 \mathrm{~mm}$ in thickness. A secondary serous retinal detachment involved most of the inferior fundus. The clinical impression of malignant melanoma of the choroid was supported by fluorescein angiography and ultrasonography. Systemic evaluation and laboratory studies were negative for extraocular melanoma.

On 17 November 1975 the involved right eye was enucleated following a strongly positive ${ }^{32} \mathrm{P}$ test. Pathological examination showed a malignant melanoma of the choroid predominantly of the spindle B cell type with slight scleral invasion but no extraocular extension of the tumour (Fig. 1). In April 1983 the patient was alive and well with no evidence of metastatic disease.

CASE 2 (WIFE)

A 58-year-old white woman, the wife of the preceding patient, first noticed the onset of blurred vision in the left eye in January 1982 and consulted her local ophthalmologist shortly after. He detected a fundus mass in the left eye and referred the patient for further consultation. Her past medical history and family history were negative with no relatives having cancer. The patient had worked for several 


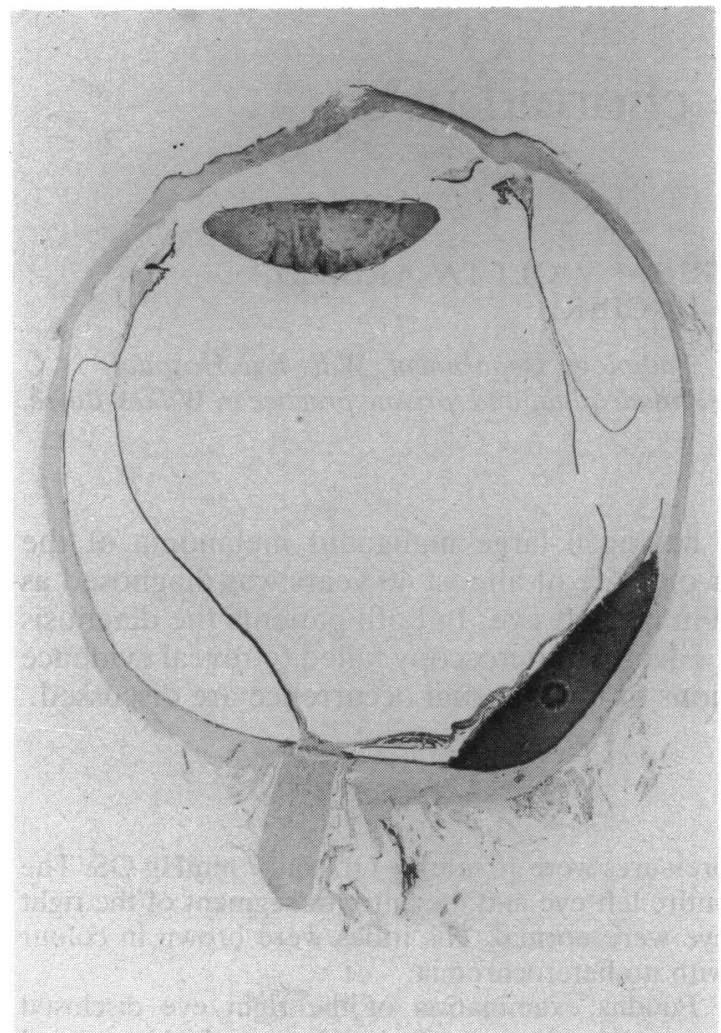

Fig. 1 Husband's eye showing choroidal melanoma in macular region $(\times 6)$.

years as an assembly tester, which involved looking through a microscope at metal discs for several hours each day. Both she and her husband had spent their entire lives in north-eastern Pennsylvania.

Ocular examination revealed best corrected visual acuities of $6 / 6$ in the right eye and 6/15 in the left eye. Intraocular pressures were $16 \mathrm{mmHg}$ in both eyes. The anterior segment of each eye and the fundus of the right eye were normal. Her irides were hazel in colour with no heterochromia.

Ophthalmoscopy of the left eye disclosed a mushroom-shaped, grey-brown choroidal mass arising from the equatorial region temporally and extending posteriorly to the macular area. A secondary bullous retinal detachment involved more than one half of the fundus inferiorly. The tumour was about $12 \mathrm{~mm}$ in basal diameter and $10 \mathrm{~mm}$ in maximal thickness. The clinical diagnosis of malignant melanoma of the choroid was supported by fluorescein angiography and ultrasonography. Systemic evaluation and laboratory studies were negative for extraocular melanoma.

On 28 January 1982 the involved left eye was

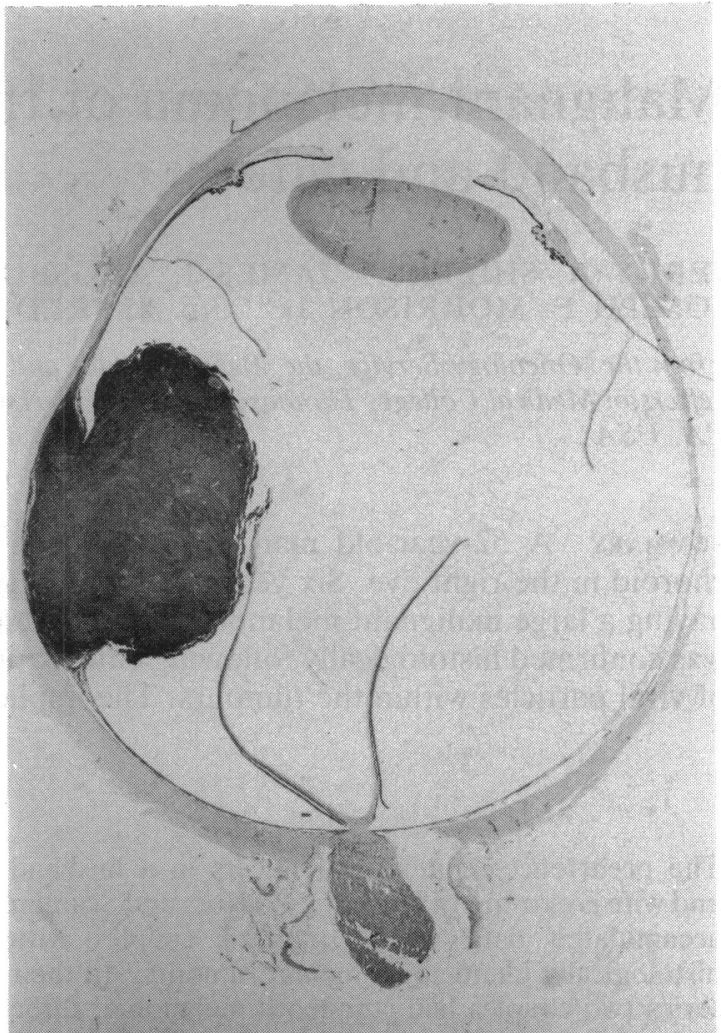

Fig. 2 Wife's eye showing mushroom-shaped choroidal melanoma $(\times 6)$.

enucleated by the cryoring technique following a strongly positive ${ }^{32} \mathrm{P}$ test of $561 \%$ uptake. Pathological examination showed a mixed cell type of choroidal melanoma composed predominantly of spindle B cells. There was no evidence of extrascleral extension (Fig. 2). The patient was alive and systemically well in April 1983 approximately 15 months after enucleation.

A piece of each tumour was removed from the paraffin blocks and processed for transmission electron microscopy. These specimens were fixed in glutaraldehyde in phosphate buffer at ph $7 \cdot 4$, postfixed in $1 \%$ osmium, dehydrated, and embedded in Araldite resin. The tissue blocks were thin sectioned and stained with uranyl acetate and lead citrate and examined in a Siemens Elmiskop 101 electron microscope. No viral particles could be detected in either tumour.

\section{Discussion}

A number of cancers have been recognised to occur with greater frequency among blood relatives. The 
occurrence of cancer in spouses, however, is relatively rare. In 1959 Nash reviewed a large series of patients with various cancers in an attempt to determine the importance of shared domestic environmental factors in the aetiology of cancers. He concluded that there was no evidence to confirm the hypothesis that domestic factors or habits common to husband and wife were carcinogenic. ${ }^{3}$ Subsequently, there were sporadic reports of cutaneous melanomas in spouses. In 1971 Robertson reported on a man and wife both of whom died from cutaneous melanoma. ${ }^{4}$ Bauman in the same year reported on a man and his adopted brother, who were not blood relatives, who both developed cutaneous melanoma. ${ }^{5}$ Later Robinson and Manheimer added a second case of cutaneous melanomas in a man and wife. ${ }^{6}$ In 1978 Smart and Carle added yet another case of connubial cutaneous melanoma and suggested that environmental factors may play a role in their occurrence. ${ }^{7}$ In 1978 Mintzis and associates reported three married couples where both spouses developed cutaneous malignant melanomas. ${ }^{8}$ They calculated that the observed number exceeded by six times the number of spouses expected to develop melanoma.

There have been a few reports of uveal melanomas occurring in blood relatives, most of which are cited in the more recent literature. ${ }^{913}$ We have seen six such cases on our Ocular Oncology Service (unpublished data). We are unaware of any previously reported cases of connubial uveal melanomas. We have been told of an unpublished occurrence, however, of uveal melanomas in a husband and wife (R. Sloan Wilson, personal communication, 1982). ${ }^{14}$

We have no apparent explanation for the occurrence of uveal melanoma in the husband and wife described in this report. Neither patient had a strong family history of cancer. It is of interest that both patients had been exposed to bright lights in their occupations, the husband working as a welder and the wife using a microscope. However, we have no valid reason to implicate their occupations in the pathogenesis of the uveal melanomas. Electron microscopical evaluation of the tumour from each patient failed to reveal viral particles or other findings which helped us understand the pathogenesis.

Of more than 1000 uveal melanoma patients seen on the Oncology Service at Wills Eye Hospital since 1974 this is the only instance in which spouses were affected. If other such cases are reported in the future common aetiological factors may possibly become evident. Until then we must assume that the unusual occurrence of connubial uveal melanoma in our patients is coincidental.

We thank Dr Joseph Morrison Sr, Dr Vitaliano Bernardino, Dr Robert Folberg, and Ms Annette Berardi for their assistance.

This investigation was supported in part by the Pennsylvania Lions Sight Conservation and Eye Research Foundation Inc, and the Ocular Oncology Fund, Wills Eye Hospital.

\section{References}

1 Russ JE, Scanlon EF. Identical cancers in husband and wife. Surg Gynecol Obstet 1980; 150: 664-6.

2 Shields JA. Introduction to melanocytic tumors of the uvea. Diagnosis and management of intraocular tumors. St Louis: Mosby, 1983: chapter 4.

3 Nash FA. The occurrence of cancer in husbands and wives. $\mathrm{Br} J$ Cancer 1959; 13: 577-88.

4 Robertson MG. Malignant melanoma in husband and wife. JAMA 1971; 217: 1553.

5 Bauman L. Melanoma in relatives. JAMA 1971; 218: 1300-1.

6 Robinson MJ, Mannheimer L. Familial melanomas. JAMA 1972; 220: 227.

7 Smart CR, Carle BN. Malignant melanoma in husband and wife. JAMA 1975; 232: 705-6.

8 Mintzis MJ, Berger AP, Greenwald E, Golomb F. Malignant melanoma in spouses. Cancer 1978; 42: 804-7.

9 Bowen SF, Brady H, Jones VL. Malignant melanoma of the eye occurring in two successive generations. Arch Ophthalmol 1964; 71: $804-6$.

10 Lynch HT, Anderson DE, Krush AJ. Heredity and intraocular melanoma. Cancer 1968; 21: 119-25.

11 Tasman WS. Familial intraocular melanoma. Trans Am Acad Ophthalmol Otolaryngol 1970; 74: 955-8.

12 Walker JP, Weiter JJ, Albert DM, Osborn EL, Weischelbaum RR. Uveal malignant melanoma in three generations of the same family. Am J Ophthalmol 1979; 88: 723-6.

13 Green GJ, Hong WK, Everett JR, Bhutani R, Ameck RM. Familial intraocular malignant melanoma. A case report. Cancer 1978; 41: 2481-3.

14 Singleton EM, Wilson RS. Contemporaneous choroidal melanoma in a former husband and wife. Presented at the Section on Ophthalmology at the 38th Annual Meeting of the Southern Medical Association, San Antonio TX, 19 November 1980. 